\title{
Stereochemical Inversion of Rim-Differentiated Pillar[5]arene Molecular Swings
}

\author{
Ke Du, " Paul Demay-Drouhard," Kushal Samanta, Shunshun Li, Tushar Ulhas Thikekar, Haiying Wang, \\ Minjie Guo, Barend van Lagen, Han Zuilhof,* and Andrew C.-H. Sue*
}

Cite This: J. Org. Chem. 2020, 85, 11368-11374

Read Online

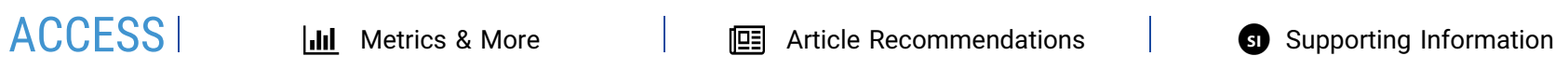

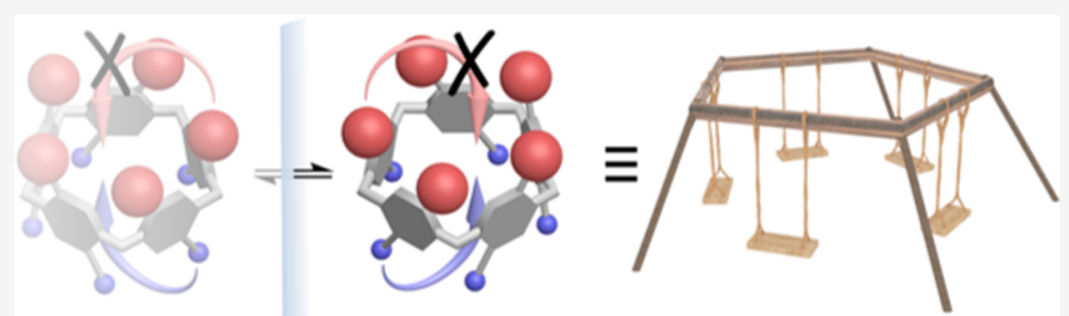

ABSTRACT: To investigate the dynamic stereochemical inversion behavior of pillar[5]arenes ( $\mathrm{P}[5]$ s) in more detail, we synthesized a series of novel rim-differentiated $\mathrm{P}[5]$ s with various substituents and examined their rapid rotations by variabletemperature NMR (203-298 K). These studies revealed for the first time the barrier of "methyl-through-the-annulus" rotation $\left(\Delta G^{\ddagger}\right.$ $=47.4 \mathrm{~kJ} \cdot \mathrm{mol}^{-1}$ in acetone) and indicated that for rim-differentiated $\mathrm{P}[5] \mathrm{s}$ with two types of alkyl substituents, the smaller rim typically determines the rate of rotation. However, substituents with terminal $\mathrm{C}=\mathrm{C}$ or $\mathrm{C} \equiv \mathrm{C}$ bonds give rise to lower inversion barriers, presumably as a result of attractive $\pi-\pi$ interactions in the transition state. Finally, data on a rim-differentiated pentamethyl-penta-propargyl $\mathrm{P}[5]$ exhibited the complexity of the overall inversion dynamics.

\section{INTRODUCTION}

Pillar $[5] \operatorname{arene}^{1}(\mathrm{P}[5] \mathrm{s})$, consisting of five repeating parasubstituted hydroquinone units connected by methylene bridges, are a class of macrocycles with intriguing dynamic stereochemical properties. ${ }^{2}$ In the solid state, the $\mathrm{P}[5]$ scaffold forms its characteristic name-giving hollow pillar-like structure, with all five hydroquinone units aligned, as a result of both steric hindrance and guest inclusion. ${ }^{1}$ While a near-constant pillar shape is observed with alkoxy groups on both sides, this conformation is not observed anymore if the alkyl substituents are (partially) removed to expose phenolic $-\mathrm{OH}$ groups for intramolecular hydrogen bonding, ${ }^{3}$ or when one of the rims has only $\mathrm{C}-\mathrm{H}$ functionalization, as shown in recently synthesized tiara[5] arenes. ${ }^{4}$ Such structural variability reflects the rich conformational isomerism of $\mathrm{P}[5] \mathrm{s},{ }^{5}$ as the hydroquinone planes may rotate and adopt various angles relative to the overall pentagonal scaffold in solution.

Different from calix $[n]$ arenes, ${ }^{6}$ on which additional substituents have to be grafted to break internal mirror planes, $\mathrm{P}[5] \mathrm{s}$ are inherently chiral ${ }^{7}$ regardless of their functionalization patterns. The chirality of the $\mathrm{P}[5]$ scaffold with respect to a plane of symmetry $\sigma$ arises from its nonplanar conformations, which contain neither plane nor center of symmetry. Enantiomeric P [5] conformers are interconvertible to each other through a sequence of "substituent-through-the-annulus" inside-out and outside-in rotations (Figure 1). This motion is
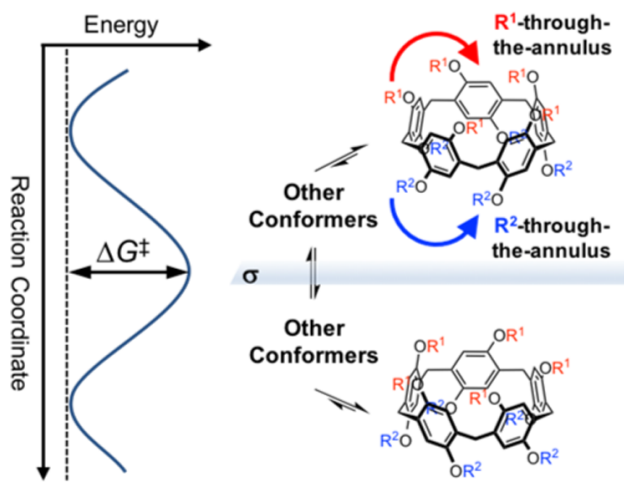

Figure 1. Schematic representation of the stereochemical inversion between enantiomeric conformers of pillar[5]arene and the idealized energy curve of the inversion process. The hydroquinone units flip by way of " $\mathrm{R}^{1} / \mathrm{R}^{2}$-through-the-annulus" motions: $\mathrm{R}^{1}$ moves either through the cavity while $R^{2}$ goes along the outside (top route in red) or the other way around (bottom route in blue).

Received: June 20, 2020

Published: August 21, 2020 
complicated in nature: before the first ring has fully rotated, the second already starts to rotate to minimize any incurred steric hindrance between adjacent rings. Along this interconversion path, multiple transition states and intermediates may be observed, depending on the nature of the substituents. ${ }^{8}$ When the inversion energy barriers are not high enough to hinder such movements, in solution, $\mathrm{P}[5] \mathrm{s}$ are stereolabile, undergoing rapid enantiomerization ${ }^{9}$ or diastereoisomerization ${ }^{10}$ when chiral substituents are attached onto the $\mathrm{P}[5]$ scaffold, under thermodynamic equilibrium.

In 2010, Ogoshi and co-workers systematically investigated $^{11}$ the stereochemical inversion processes of a series of per-functionalized $\mathrm{P}[5]$ s with different $n$-alkyl chain lengths by dynamic NMR (DNMR). The rotation barriers derived from the corresponding coalescence temperatures $\left(T_{c}\right)$ range from 46.3 (ethyl) to 63.2 ( $n$-dodecyl) $\mathrm{kJ} \cdot \mathrm{mol}^{-1}$, showing a monotonic increase of the inversion barrier with the increase of the $n$-alkyl chain length. Nonetheless, the inversion barrier of per-methyl-P $[5]$, ${ }^{\text {la }}$ one of the most widely used $\mathrm{P}[5] \mathrm{s}$ on account of its high-yielding facile synthesis, could not be accurately determined, since its overall structure does not contain any diastereotopic ${ }^{1} \mathrm{H}$ probes for DNMR study. The energy barrier for rotation of A1-/A2-dihydroxy-octamethyl $\mathrm{P}[5]\left[\mathrm{A} 1 / \mathrm{A} 2^{3 \mathrm{~b}, 12}\right.$ refers to both hydroxy groups being bound to the same aryl ring, and located at different rims] was reported $^{13}$ by Stoddart et al. in 2013 to be $49.7 \mathrm{~kJ} \cdot \mathrm{mol}^{-1}$ in $\mathrm{CDCl}_{3}$. The interactions provided by intramolecular hydrogen bonds were found to significantly impact the stereochemical inversion barriers of these difunctionalized $\mathrm{P}[5]$ derivatives. When the substituents on $\mathrm{P}[5]$ s are bulky enough to enable successful chiral resolution, inversion energy barriers canapart from by DNMR - also be determined ${ }^{14}$ by monitoring the racemization process using circular dichroism spectroscopy or HPLC with chiral stationary phases.

So far, only per-functionalized ${ }^{15}$ and A1/A2-disubstituted $\mathrm{P}[5] \mathrm{s}^{3 \mathrm{~b}, 12}$ have been studied by DNMR for their inversion processes, since most other $\mathrm{P}[5]$ functionalization patterns with low symmetry result in complicated NMR spectra whose assignments remain nontrivial. Rim-differentiated $\mathrm{P}[5] \mathrm{s},{ }^{16}$ whose two rims are decorated with different functionalities, represent another type of highly symmetric $\mathrm{P}[5]$ species. Such rim differentiation is desirable for a number of applications, and we thought to make use of this platform for dynamic stereochemical studies on account of its two nondegenerate rotational modes, e.g., $\mathrm{R}^{1}$-through-the-annulus and $\mathrm{R}^{2}$-throughthe-annulus (Figure 1). However, progress on DNMR studies of such rim-differentiated $\mathrm{P}[5] \mathrm{s}$ was hampered by their inefficient syntheses and difficult purification steps. In recent years, our research group has developed ${ }^{17}$ efficient methods for the synthesis and derivatization of $C_{5}$-symmetric rim-differentiated $\mathrm{P}[5] \mathrm{s}$ that largely overcome these limitations.

Taking advantage of this unique molecular scaffold, in this paper, we report rim-differentiated $\mathrm{P}[5]$-based "molecular pentagonal swings" with restricted rocking motions. These specifically synthesized compounds allow for the determination of unattainable inversion barriers by variable-temperature ${ }^{1} \mathrm{H}$ NMR studies (203-298 K), differentiate the roles of size and presence of $\pi$-electrons, and indicate a far greater complexity of the rotation behavior than anticipated.

\section{RESULTS AND DISCUSSION}

Synthesis. First, a series of rim-differentiated $\mathrm{P}[5] \mathrm{s}$ 1a-1e were synthesized (Scheme 1) using the methodology we
Scheme 1. (a) Syntheses of Rim-Differentiated Pillar[5] arenes and (b) Per-Functionalized Pillar[5]arenes under Current Study

(a)

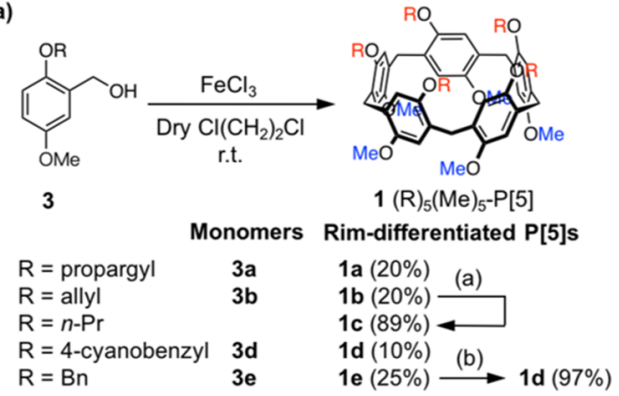

Procedure a: $\mathrm{H}_{2}, \mathrm{Pd} / \mathrm{C}, \mathrm{EtOAc}, 25^{\circ} \mathrm{C}, 24 \mathrm{~h}$. Procedure b: 1) $\mathrm{H}_{2}$, $\mathrm{Pd} / \mathrm{C}$, EtOAc, $25^{\circ} \mathrm{C}, 4 \mathrm{~h}$; 2) $\mathrm{NaOH}, \mathrm{H}_{2} \mathrm{O}, 60{ }^{\circ} \mathrm{C}, 30 \mathrm{~min}$; 3) 4cyanobenzyl bromide (10.0 eq.), $\mathrm{MeCN}, 60^{\circ} \mathrm{C}, 12 \mathrm{~h}$.

(b)

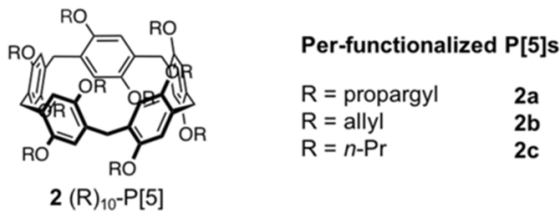

recently developed. ${ }^{17}$ Per-functionalized $\mathrm{P}[5] \mathrm{s} \mathbf{2 a}-\mathbf{2 c}$ were prepared by following the procedures reported in the literature. ${ }^{11,18}$ We briefly describe this procedure for one of the compounds under study, a rim-differentiated $\mathrm{P}[5]$ with 4cyanobenzyl moieties on one rim and methyl groups on the other, (4-cyanobenzyl $)_{5}(\mathrm{Me})_{5}-\mathrm{P}[5]$ 1d (see also the Experimental Section). Compound 1d was obtained through two synthetic routes. The first one involved the $\mathrm{FeCl}_{3}$-catalyzed cyclization of the corresponding asymmetrically substituted 2,5-dialkoxybenzyl alcohol according to our previously synthesized "preoriented" procedure ${ }^{17 a}$ and generated the expected product in $10 \%$ yield after careful column chromatography. The other pathway entailed the synthesis of generic building block (benzyl) $)_{5}(\mathrm{Me})_{5}-\mathrm{P}[5] \mathbf{1 e}^{16 \mathrm{c}, 17 \mathrm{~b}}$ - as this can easily be obtained on a gram scale, with $25 \%$ isolated yield-followed by a highly efficient two-step debenzylation/ realkylation ${ }^{17 b}$ with 4-cyanobenzyl bromide, affording (4cyanobenzyl $)_{5}(\mathrm{Me})_{5}-\mathrm{P}[5]$ 1d in a near-quantitative yield. This superior yield along with a much easier purification step (precipitation from hot EtOAc) makes this indirect route highly preferable.

Dynamic NMR Studies. In our molecular design for (4cyanobenzyl $)_{5}(\mathrm{Me})_{5}-\mathrm{P}[5]$ 1d, the 4-cyanobenzyl groups serve as stoppers that are too bulky to enter the $\mathrm{P}[5]$ cavity, and its benzylic geminal protons can be employed as the ${ }^{1} \mathrm{H}$ DNMR probe. On the other hand, the "methyl-through-the-annulus" movement of the other rim seems hardly affected (see Figure 2a). Instead of continuous full rotations, the stereochemical inversion of the $\mathrm{P}[5]$ scaffold can still happen through backand-forth rocking resembling that of swings on the macroscopic scale.

To further verify that the 4-cyanobenzyl group is an effective stopper of the rotational motion, single-crystal samples of (4cyanobenzyl $)_{5}(\mathrm{Me})_{5}-\mathrm{P}[5] \quad 1 d$ were obtained and then elucidated (Figure $2 \mathrm{~b}$ ) by X-ray crystallography to provide detailed information of its molecular geometry. In the solid state, the $\mathrm{P}[5]$ macrocyclic scaffold adopts the typical pillar-like shape containing a $n$-hexane guest in the cavity. The distance between the center of a hydroquinone unit and the nitrogen 
(a)

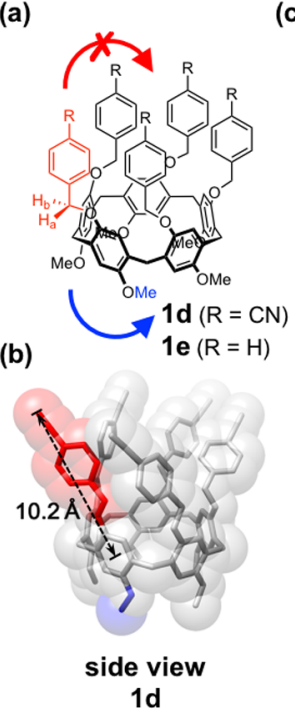

Figure 2. (a) Stereochemical inversions of $\mathbf{1 d}$ can be completed with predominant "methyl-through-the-annulus" rotations, while similar movements of the other 4-cyanobenzyl side were suppressed. (b) Side views of crystal structure of $\mathbf{1 d}$, where the distance between $\mathrm{N}$ atom and center of aromatic unit on the $\mathrm{P}[5]$ scaffold is $10.2 \AA$ and the cavity size is $5.5 \AA$. (c) Partial DNMR spectra of $\mathrm{H}_{\mathrm{a}} / \mathrm{H}_{\mathrm{b}}$ on $\mathbf{1 d}$ from 298 down to $203 \mathrm{~K}$ in acetone- $d_{6}$. (d) Partial DNMR spectra of 1 e from 298 down to $213 \mathrm{~K}$ in toluene- $d_{8}$.

atom on the tip of the 4-cyanobenzyl group is $10.2 \AA$, which is larger than the roughly $5.5 \AA$ opening of the $\mathrm{P}[5]$ macrocycle (see Figure $2 \mathrm{~b}$ ). Furthermore, a difunctionalized $\mathrm{P}[5]$ with two 4-cyanobenzyl moieties attached on both sides of one particular hydroquinone unit, namely, A1/A2-bis(4-cyanobenzyl)-P[5] 1d', was also synthesized (see the Experimental Section) for DNMR studies. A clear AB system of ${ }^{1} \mathrm{H}$ NMR signals of the $-\mathrm{OCH}_{2}-$ methylene protons was still observed (see the Supporting Information) at an elevated temperature of $367 \mathrm{~K}$, indicating that even at that temperature, the geminal $-\mathrm{OCH}_{2}-$ protons exchange only slowly on the NMR time scale. These experiments both suggest that the size of the oxygen-bound 4-cyanobenzyl substituent is sufficient to block the dynamic stereochemical inversion when attached to $\mathrm{P}[5] \mathrm{s}$.

The on-average $C_{5}$ symmetry of $\mathbf{1 d}$ renders the corresponding protons on the five repeating hydroquinone units homotopic, resulting in simple and clear NMR spectra that are easy to interpret. Variable-temperature $400 \mathrm{MHz}{ }^{1} \mathrm{H}$ NMR spectra were collected in acetone- $d_{6}$ from 203 to $298 \mathrm{~K}$ (Figure $2 \mathrm{c}$; see the Supporting Information for full spectra). As expected, the geminal protons $\mathrm{H}_{\mathrm{a}}$ and $\mathrm{H}_{\mathrm{b}}$ of the $-\mathrm{OCH}_{2}-$ methylene units are diastereotopic and anisochronous,

appearing as two doublets in the NMR spectra recorded at lower temperatures. The inversion processes become faster and increasingly relevant on the NMR time scale as the temperature increases, and the fast exchange of the chemical environment surrounding protons $\mathrm{H}_{a}$ and $\mathrm{H}_{\mathrm{b}}$ causes coalescence of their ${ }^{1} \mathrm{H}$ NMR signals at $4.69 \mathrm{ppm}$ at $240 \mathrm{~K}$. Above the coalescence temperature $\left(T_{\mathrm{c}}\right)$, the $-\mathrm{OCH}_{2}-$ proton signals eventually converge into a sharp singlet. Since the stereochemical inversion of the "molecular pentagonal swings" is only accessible through "methyl-through-the-annulus" motions, the value of the barrier $\left(\Delta G^{\ddagger}\right)$ calculated (Table 1) from the DNMR data, $47.3 \mathrm{~kJ} \cdot \mathrm{mol}^{-1}$, should therefore also serve as a reasonable estimation of the inversion barrier of permethyl-P $[5]$ in acetone- $d_{6}$. Owing to the poor solubility of $\mathbf{1 d}$, attempts to determine its inversion barrier in toluene- $d_{8}$ were not successful. Instead, rim-differentiated (benzyl) $)_{5}(\mathrm{Me})_{5}-\mathrm{P}[5]$ 1e with five benzyl groups ${ }^{19}$ was subjected (Figure $2 \mathrm{~d}$ ) to DNMR measurements in toluene- $d_{8}$, and the corresponding $T_{c}$ and $\Delta G^{\ddagger}$ were found (Table 1 ) to be $250.5 \mathrm{~K}$ and $49.6 \mathrm{~kJ}$. $\mathrm{mol}^{-1}$, respectively.

To further understand the dynamic stereochemical inversion behavior of $\mathrm{P}[5] \mathrm{s}$, additional DNMR studies were carried out in toluene- $d_{8}$ on a series of rim-differentiated $\mathrm{P}[5] \mathrm{s}$ with methyl on one rim and propargyl/allyl/propyl groups on the other (compounds $\mathbf{1 a - 1 c}$ ), as well as the corresponding perfunctionalized $\mathrm{P}[5] \mathrm{s} \mathbf{2 a - 2 c}$ with propargyl/allyl/propyl substituents.

Their coalescence temperatures and inversion barriers are summarized in Table 1, and full NMR spectra are available in the Supporting Information. The DNMR measurement of perfunctionalized (propyl) ${ }_{10}-\mathrm{P}[5]$ 2c shows (Figure 3a) a coalescence temperature at $258 \mathrm{~K}$ and a corresponding inversion barrier of $51.8 \mathrm{~kJ} \cdot \mathrm{mol}^{-1}$, which is within the $\pm 1 \mathrm{~kJ}$. $\mathrm{mol}^{-1}$ error range of the DNMR method compared to the value of $50.9 \mathrm{~kJ} \cdot \mathrm{mol}^{-1}$ reported $^{11}$ by Ogoshi on the same compound. Nonetheless, the $-\mathrm{OCH}_{2}-$ geminal proton NMR signals of per-functionalized (propargyl) ${ }_{10}-\mathrm{P}[5] \quad 2 \mathrm{a}$ and (allyl) ${ }_{10}-\mathrm{P}[5]$ 2b did not show (Figure $3 \mathrm{~b}, \mathrm{c}$ ) any splitting even down to $203 \mathrm{~K}$, suggesting that rotations of their hydroquinone units still occur faster than the NMR time scale, and their $\Delta G^{\ddagger}$ values are even smaller than the lower detection limit around $40 \mathrm{~kJ} \cdot \mathrm{mol}^{-1}$. Given the minor difference between propyl and propargyl/allyl groups in terms of size, this indicates that-in addition to steric hindrance and hydrogen bonds-the presence of $\pi$ electrons might favorably interact with the aryl $\pi$ electrons during the rotation process, exerting considerable influence on the rate of the rim inversion process. These experimental results further substantiate our previous theoretical investigations on $\mathrm{P}[5]$ rotational energy profiles, ${ }^{8}$ which indicated that "the stabilization of the intermediate

Table 1. Dynamic NMR Studies and Derived Kinetic Parameters for the Through-Annulus Rotation of Various RimDifferentiated (Compounds 1a-1e) and Per-Functionalized $(2 a-2 c)$ Pillar [5]arenes

\begin{tabular}{|c|c|c|c|c|c|c|c|c|c|}
\hline $\mathrm{P}[5]$ & \multicolumn{2}{|c|}{$1 a^{a}$} & $1 b^{a}$ & $1 c^{a}$ & $1 d^{b}$ & $1 \mathrm{e}^{a}$ & $2 a^{a}$ & $2 \mathbf{b}^{a}$ & $2 c^{a}$ \\
\hline$T_{\mathrm{c}}(\mathrm{K})$ & $238^{c}$ & $233^{d}$ & & 238 & 240 & 250.5 & & & 258 \\
\hline$\Delta \nu(\mathrm{Hz})$ & 65.6 & 26.0 & & 80.0 & 90.4 & 88.0 & & & 65.2 \\
\hline$k_{\text {coal }}\left(\mathrm{s}^{-1}\right)$ & 159.6 & 87.1 & & 182.8 & 211.7 & 207.2 & & & 150.5 \\
\hline$t_{1 / 2}(\mathrm{~ms})$ & 4.3 & 8.0 & & 3.8 & 3.3 & 3.3 & & & 4.5 \\
\hline$\Delta G^{\ddagger}(\mathrm{kJ} / \mathrm{mol})$ & 47.6 & 48.4 & $<40$ & 47.2 & 47.4 & 49.6 & $<40$ & $<40$ & 51.8 \\
\hline
\end{tabular}

${ }^{a}$ Solvent: toluene- $d_{8} \cdot{ }^{b}$ Solvent: acetone- $d_{6} \cdot{ }^{c}$ Two datasets of $\mathbf{1 a}$ were obtained from the NMR signal of $\mathrm{H}_{\mathrm{a}} / \mathrm{H}_{\mathrm{b}} \cdot{ }^{d}$ Two datasets of $\mathbf{1 a}$ were obtained from the NMR signal of $\mathrm{H}_{\mathrm{c}} / \mathrm{H}_{\mathrm{d}}$. 


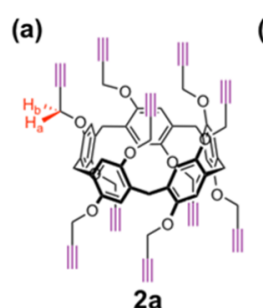

(b)

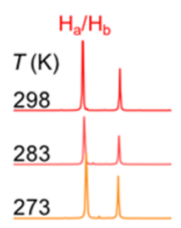

$263 \longleftrightarrow$

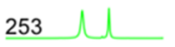

$243 \sim$

233 u

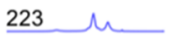

213 m

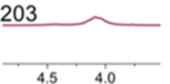

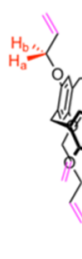

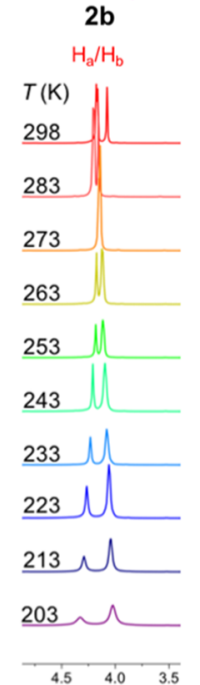

Chemical Shift / ppm (c)

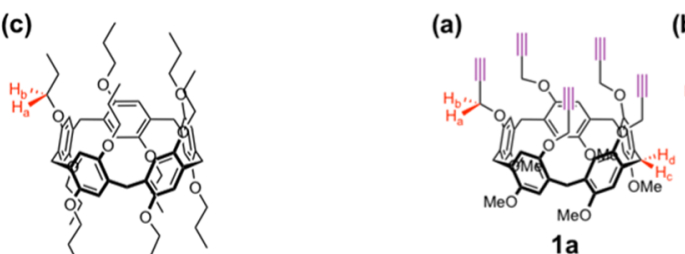

2c
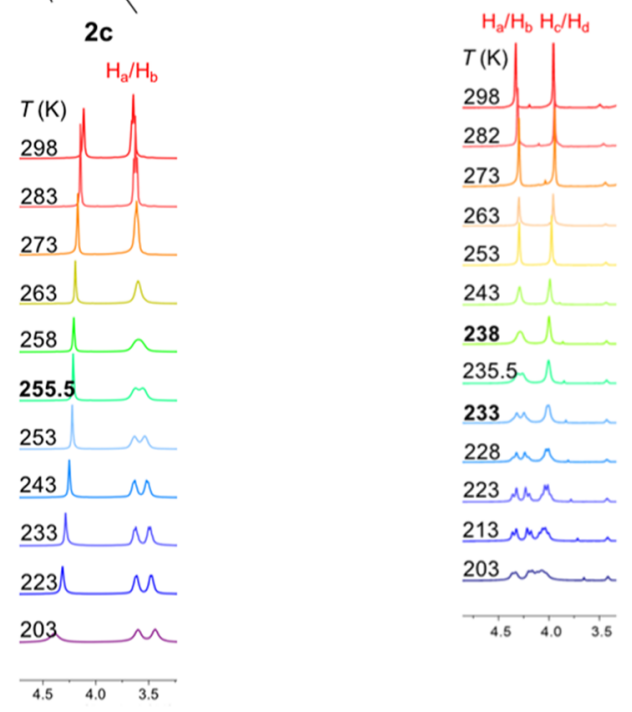

Figure 3. Partial DNMR spectra of (a) 2a, (b) $2 \mathbf{b}$, and (c) 2 c from 298 down to $203 \mathrm{~K}$ in toluene- $d_{8}$.

structures by noncovalent van der Waals interactions, as well as by hydrogen bonds, constitutes a major factor affecting barrier heights."

From the DNMR studies above, we have established the "Rthrough-the-annulus" $\Delta G^{\ddagger}$ values for $\mathrm{P}[5]$-rims functionalized with different short hydrocarbon chains in the following order: propyl $\left(51.8 \mathrm{~kJ} \cdot \mathrm{mol}^{-1}\right.$ in toluene- $\left.d_{8}\right)>\operatorname{methyl}\left(49.6 \mathrm{~kJ} \cdot \mathrm{mol}^{-1}\right.$ in toluene- $d_{8}$ or $47.4 \mathrm{~kJ} \cdot \mathrm{mol}^{-1}$ in acetone- $\left.d_{6}\right)>$ allyl/propargyl $\left(<40 \mathrm{~kJ} \cdot \mathrm{mol}^{-1}\right.$ in toluene- $\left.d_{8}\right)$. For rim-differentiated $\mathrm{P}[5] \mathrm{s}$ with two nondegenerate rotational modes, it is anticipated that the substituent with the lower barrier height should dominate the inversion processes. This is indeed the case for $\mathbf{1 b}$ and $\mathbf{1 c}$ (see Table 1 and Figure 4$)$. The energy barrier of $(n-\mathrm{Pr})_{5}(\mathrm{Me})_{5}$ $\mathrm{P}[5] 1 \mathrm{c}$ is $47.2 \mathrm{~kJ} \cdot \mathrm{mol}^{-1}$, which is $4.6 \mathrm{~kJ} \cdot \mathrm{mol}^{-1}$ lower than the "propyl-through-the-annulus" value (observed for $(n-\mathrm{Pr})_{10^{-}}$ $\mathrm{P}[5] 2 \mathrm{c}$ ). Similar to the case of per-functionalized (allyl) $10^{-}$ $\mathrm{P}[5] \mathbf{2 b}$, the rim-differentiated (allyl) ${ }_{5}(\mathrm{Me})_{5}-\mathrm{P}[5] \mathbf{1 b}$ also displays rapid rotations in the temperature range studied, as a result of the low inversion barrier of the allyl-functionalized rim.

The rim-differentiated (propargyl) ${ }_{5}(\mathrm{Me})_{5}-\mathrm{P}[5] \mathbf{1 a}$, nonetheless, displays anomalous behavior. Instead of being dominated by the propargyl groups, which would be expected to provide a low-energy pathway for fast rotation, the inversion slows down significantly at lower temperatures, and coalescence of the $-\mathrm{OCH}_{2}-$ protons was observed (Figure $4 \mathrm{a}$ ) at $238 \mathrm{~K}$, which corresponds to an energy barrier of $47.6 \mathrm{~kJ} \cdot \mathrm{mol}^{-1}$ (Table 1 ). Moreover, it is noteworthy that the $\mathrm{Ar}-\mathrm{CH}_{2}-\mathrm{Ar}$ protons of $\mathbf{1 a}$ were also found (Figure 4a) to be anisochronous, splitting into two sets of doublets at lower temperatures. A $T_{c}$ of $233 \mathrm{~K}$ and a $\Delta G^{\ddagger}$ value of $48.4 \mathrm{~kJ} \cdot \mathrm{mol}^{-1}$ were found for the $\mathrm{Ar}-\mathrm{CH}_{2}-\mathrm{Ar}$ geminal protons, in which the combination of lower $T_{\mathrm{c}}$ and higher $\Delta G^{\ddagger}$ resulted from the significant difference in $\Delta v$

(b)
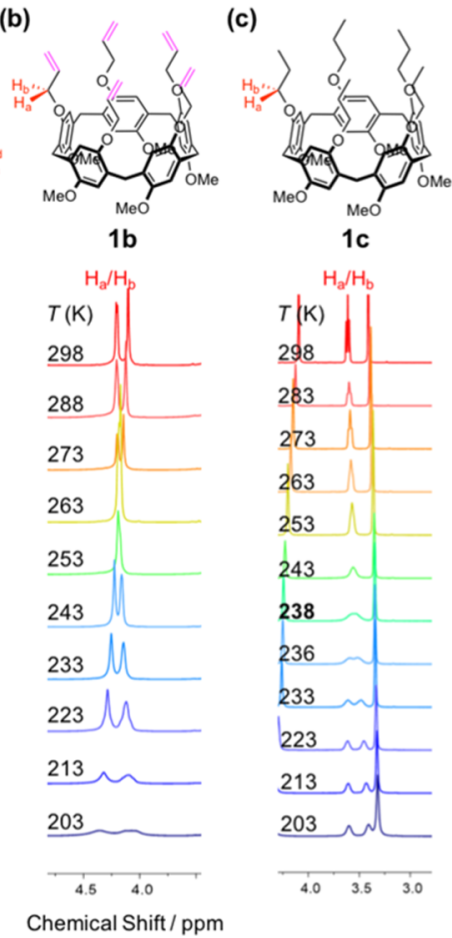

Figure 4. Partial DNMR spectra of (a) 1a, (b) 1b, and (c) 1c from 298 down to $203 \mathrm{~K}$ in toluene- $d_{8}$.

values for these two sets of protons (at the coalescence temperature, $\Delta v=26.0 \mathrm{~Hz}$ for the $\mathrm{Ar}-\mathrm{CH}_{2}-\mathrm{Ar}$ protons, and $\Delta v=65.6 \mathrm{~Hz}$ for the $-\mathrm{OCH}_{2}-$ protons; see eq 1 , Experimental Section). Although the methylene bridge protons of rim-differentiated $\mathrm{P}[5] \mathrm{s}$ are, in principle, always diastereotopic to each other, so far 1a is the only compound that shows this phenomenon, which also allows observation of this complex dynamic behavior in our DNMR studies. Both $\Delta G^{\ddagger}$ values obtained for $\mathbf{1 a}$ are higher than the "propargyl-throughthe-annulus" barrier $\left(<40 \mathrm{~kJ} \cdot \mathrm{mol}^{-1}\right)$, suggesting that the enantiomerization process of $\mathbf{1 a}$ is more complex than that of the other compounds under current study. This (highly reproducible, but) counterintuitive result is in line with our earlier theoretical findings that the mechanical movements between different $\mathrm{P}[5]$ hydroquinone units are not mutually independent, ${ }^{8}$ and it confirms that not only the transition-state energy but also that of starting conformations and unexpectedly stable intermediates need to be taken into account to fully describe the complex dynamics of these materials (see the Supporting Information for the DFToptimized structure of 1a). Given the relatively small size of this effect, a thorough understanding thereof might require indepth theoretical investigations at a high level of theory.

\section{CONCLUSIONS}

Using tailor-made rim-differentiated and per-functionalized pillar[5]arenes, we demonstrated that whereas the interconversion of enantiomeric pillar[5] arene conformers typically proceeds by moving the sterically smallest substituent through the cavity, the energy barrier for this process is in fact dominated by the contribution of the "fastest" substituents, i.e., the smallest one or the one that provides most stabilization in the transition state, e.g., by attractive $\pi-\pi$ interactions between the substituent and aryl rings. However, the interconversion is a complex process, in which substituents may interact 
competitively or cooperatively in many ways, yielding inextricably intertwined motions during the inversion process and concomitantly occasional "outliers" in the overall activation barriers. These findings thus shed more light on the complex nature of the dynamic process of pillar[5] arene stereochemical inversion and may provide future design guidance for pillararene-based chiral sensors ${ }^{20}$ and molecular switches and machines. $^{21}$

\section{EXPERIMENTAL SECTION}

General Procedure. Starting materials, reagents, and solvents were purchased from commercial vendors and used as received, unless otherwise noted. All reactions that required heating employed an oil bath. Analytical thin-layer chromatography (TLC) was performed on aluminum sheets, precoated with silica gel GF254. Flash column chromatography was performed over silica gel (200-300 mesh or 300-400 mesh). The chemical shifts are listed in parts per million (ppm) on the $\delta$ scale, and coupling constants were recorded in hertz $(\mathrm{Hz})$. Chemical shifts are calibrated relative to chloroform $\left(\mathrm{CDCl}_{3}: \delta\right.$ $7.26 \mathrm{ppm}$ for ${ }^{1} \mathrm{H}$ and $77.16 \mathrm{ppm}$ for ${ }^{13} \mathrm{C}$ ).

A1/A2-bis(4-cyanobenzyl)-P[5] 1d': In a sealed tube were introduced A1/A2-dihydroxy-octamethyl $\mathrm{P}[5]^{12 \mathrm{~b}}$ (200 mg, 0.277 mmol, 1.0 equiv), 4-cyanobenzyl bromide $(271 \mathrm{mg}, 1.39 \mathrm{mmol}, 5.0$ equiv), $\mathrm{KI}$ (13.8 mg, $0.083 \mathrm{mmol}, 0.3$ equiv), and $\mathrm{K}_{2} \mathrm{CO}_{3}(229 \mathrm{mg}$, $1.66 \mathrm{mmol}$, 6.0 equiv). Dry $\mathrm{MeCN}(5 \mathrm{~mL})$ was added, and the resulting mixture was stirred at $115{ }^{\circ} \mathrm{C}$ for $12 \mathrm{~h}$. After cooling to 25 ${ }^{\circ} \mathrm{C}, \mathrm{H}_{2} \mathrm{O}$ was added and the crude mixture was extracted with EtOAc $(3 \times 30 \mathrm{~mL})$, dried over $\mathrm{MgSO}_{4}$, filtered, and concentrated to dryness. Column chromatography (EtOAc/ $n$-hexane, 15/85) afforded the target compound as a white solid $(152 \mathrm{mg}, 0.159 \mathrm{mmol}, 57 \%) .{ }^{1} \mathrm{H}$ NMR $\left(600 \mathrm{MHz}, \mathrm{CDCl}_{3}\right) \delta 7.65(\mathrm{~d}, J=8.2 \mathrm{~Hz}, 4 \mathrm{H}), 7.49(\mathrm{~d}, J=8.2$ $\mathrm{Hz}, 4 \mathrm{H}), 6.82(\mathrm{~s}, 2 \mathrm{H}), 6.82(\mathrm{~s}, 2 \mathrm{H}), 6.78(\mathrm{~s}, 2 \mathrm{H}), 6.75(\mathrm{~s}, 2 \mathrm{H}), 6.64$ $(\mathrm{s}, 2 \mathrm{H}), 5.02(\mathrm{~d}, J=13.3 \mathrm{~Hz}, 2 \mathrm{H}), 4.94(\mathrm{~d}, J=13.3 \mathrm{~Hz}, 2 \mathrm{H}), 3.92(\mathrm{~s}$, $1 \mathrm{H}), 3.90(\mathrm{~s}, 1 \mathrm{H}), 3.81(\mathrm{~s}, 2 \mathrm{H}), 3.77(\mathrm{~s}, 4 \mathrm{H}), 3.74(\mathrm{~s}, 1 \mathrm{H}), 3.72(\mathrm{~s}$, $1 \mathrm{H}), 3.71(\mathrm{~s}, 6 \mathrm{H}), 3.69(\mathrm{~s}, 6 \mathrm{H}), 3.50(\mathrm{~s}, 6 \mathrm{H}), 3.38(\mathrm{~s}, 6 \mathrm{H}) .{ }^{13} \mathrm{C}\left\{{ }^{1} \mathrm{H}\right\}$

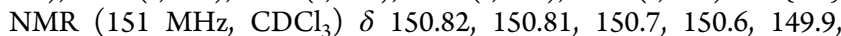
$143.5,132.3,128.7,128.6,128.3,128.2,127.43,127.38,118.8,115.2$, 114.1, 114.0, 113.9, 111.4, 69.4, 55.97, 55.96, 55.93, 55.92, 55.6, 55.4, 29.9, 29.6, 29.4. HRMS (ESI) $\mathrm{m} / z[\mathrm{M}+\mathrm{Na}]^{+}$calcd for $\mathrm{C}_{59} \mathrm{H}_{56} \mathrm{O}_{10} \mathrm{~N}_{2} \mathrm{Na}$ 975.3827, found 975.3788.

3d: To a solution of 2-hydroxy-5-methoxybenzaldehyde $(1.00 \mathrm{~g}$, $6.57 \mathrm{mmol}, 1.0$ equiv) in $\mathrm{MeCN}(40 \mathrm{~mL})$ was added $\mathrm{K}_{2} \mathrm{CO}_{3}(1.81 \mathrm{~g}$, $13.1 \mathrm{mmol}, 2.0$ equiv) followed by 4-cyanobenzyl bromide $(1.29 \mathrm{~g}$, $6.57 \mathrm{mmol}, 1.0$ equiv). The resulting mixture was refluxed for $20 \mathrm{~h}$, cooled down to $25{ }^{\circ} \mathrm{C}$, filtered, and concentrated to dryness. The crude aldehyde was dissolved in $\mathrm{MeOH}(200 \mathrm{~mL})$, to which $\mathrm{NaBH}_{4}$ ( $120 \mathrm{mg}, 3.3 \mathrm{mmol}, 0.5$ equiv) was added. The resulting mixture was stirred at room temperature for $2 \mathrm{~h}$ and concentrated to dryness. Column chromatography (EtOAc/ $n$-hexane, 20/80 to $40 / 60$ ) afforded $3 \mathrm{~d}$ as a white solid $(1.51 \mathrm{~g}, 5.61 \mathrm{mmol}, 85 \%) .{ }^{1} \mathrm{H}$ NMR $\left(400 \mathrm{MHz}, \mathrm{CDCl}_{3}\right): \delta 7.61(\mathrm{~d}, J=8.0 \mathrm{~Hz}, 2 \mathrm{H}), 7.49(\mathrm{~d}, J=8.0 \mathrm{~Hz}$, $2 \mathrm{H}), 6.95(\mathrm{~d}, J=2.9 \mathrm{~Hz}, 1 \mathrm{H}), 6.81-6.67(\mathrm{~m}, 2 \mathrm{H}), 5.07(\mathrm{~s}, 2 \mathrm{H}), 4.70$ (s, 2H), $3.72(\mathrm{~s}, 3 \mathrm{H}), 2.71(\mathrm{~s}, 1 \mathrm{H}) .{ }^{13} \mathrm{C}\left\{{ }^{1} \mathrm{H}\right\}$ NMR (101 MHz, $\left.\mathrm{CDCl}_{3}\right): \delta 154.2,149.6,142.6,132.4,130.8,127.4,118.7,114.6$, $112.8,112.7,111.5,69.5,61.0,55.6$. HRMS (ESI) $\mathrm{m} / z[\mathrm{M}+\mathrm{Na}]^{+}$ calcd for $\mathrm{C}_{16} \mathrm{H}_{15} \mathrm{O}_{3} \mathrm{NNa} 292.0944$, found 292.0944.

(4-Cyanobenzyl $)_{5}(\mathrm{Me})_{5}-\mathrm{P}[5]$ 1d: Route $A$. To a solution of $3 \mathbf{d}$ (700 mg, $2.60 \mathrm{mmol}, 1.0$ equiv) in $\mathrm{Cl}\left(\mathrm{CH}_{2}\right)_{2} \mathrm{Cl}_{2}(300 \mathrm{~mL})$ was added anhydrous $\mathrm{FeCl}_{3}$ (169 mg, $1.04 \mathrm{mmol}, 0.4$ equiv). The resulting mixture was stirred at $25^{\circ} \mathrm{C}$ for $20 \mathrm{~h}$, quenched with $\mathrm{MeOH}(5 \mathrm{~mL})$, and concentrated to dryness. Column chromatography $\left(\mathrm{CH}_{2} \mathrm{Cl}_{2} /\right.$ $\mathrm{MeOH}, 98 / 2$ to $95 / 5)$ followed by slow evaporation from a $\mathrm{CHCl}_{3}$ solution $(40 \mathrm{~mL})$ afforded $\mathbf{1 d}$ as a white solid $(60 \mathrm{mg}, 0.05 \mathrm{mmol}$, $10 \%)$. Route $B$. To a solution of (benzyl $)_{5}(\mathrm{Me})_{5}-\mathrm{P}[5] \mathbf{1 e}^{16 \mathrm{c}, 17 \mathrm{~b}}(100$ $\mathrm{mg}, 0.088 \mathrm{mmol}, 1.0$ equiv) in EtOAc $(5 \mathrm{~mL})$ was added $\mathrm{Pd} / \mathrm{C}(10 \%$ wt, wetted with $55 \% \mathrm{H}_{2} \mathrm{O}, 100 \mathrm{mg}$ ). The resulting mixture was stirred under $\mathrm{H}_{2}$ atmosphere at $25{ }^{\circ} \mathrm{C}$ for $4 \mathrm{~h}$, filtered over a pad of celite, and concentrated to dryness to afford the corresponding pentanol as a white solid (60 mg, $0.088 \mathrm{mmol}$, quant.). This compound was dissolved in $\mathrm{H}_{2} \mathrm{O}(1 \mathrm{~mL}), \mathrm{NaOH}(26.5 \mathrm{mg}, 0.662 \mathrm{mmol}, 7.5$ equiv) was added, and the resulting mixture was stirred at $60{ }^{\circ} \mathrm{C}$ for $30 \mathrm{~min}$. A solution of 4-cyanobenzyl bromide $(173 \mathrm{mg}, 0.882 \mathrm{mmol}, 10.0$ equiv) in $\mathrm{MeCN}(1 \mathrm{~mL})$ was added, and the mixture was further stirred at $60{ }^{\circ} \mathrm{C}$ for $12 \mathrm{~h}$. After being cooled down to rt, the precipitate was filtered out, and dissolved in EtOAc $(5 \mathrm{~mL})$ at $60^{\circ} \mathrm{C}$. Hexane $(50$ $\mathrm{mL}$ ) was added dropwise. The resulting precipitate was collected and washed with hexane $(10 \mathrm{~mL})$. This procedure was repeated once to afford 1d as a white solid (81 mg, 97\%). ${ }^{1} \mathrm{H}$ NMR (400 $\mathrm{MHz}$, $\left.\mathrm{CDCl}_{3}\right) \delta 7.59(\mathrm{~d}, J=8.0 \mathrm{~Hz}, 10 \mathrm{H}), 7.29(\mathrm{~d}, J=8.0 \mathrm{~Hz}, 10 \mathrm{H}), 6.76$ $(\mathrm{s}, 5 \mathrm{H}), 6.61(\mathrm{~s}, 5 \mathrm{H}), 4.50(\mathrm{~s}, 10 \mathrm{H}), 3.81(\mathrm{~s}, 10 \mathrm{H}), 3.62(\mathrm{~s}, 15 \mathrm{H})$. ${ }^{13} \mathrm{C}\left\{{ }^{1} \mathrm{H}\right\}$ NMR $\left(101 \mathrm{MHz}, \mathrm{CDCl}_{3}\right) \delta 151.7,149.4,143.1,132.4$, 129.1, 128.5, 127.6, 118.6, 115.8, 114.5, 111.9. HRMS (ESI) $\mathrm{m} / z$ [M $+\mathrm{Na}]^{+}$calcd for $\mathrm{C}_{80} \mathrm{H}_{65} \mathrm{O}_{10} \mathrm{~N}_{5} \mathrm{Na}$ 1278.4624, found 1278.4611 .

$(n-\mathrm{Pr})_{5}(\mathrm{Me})_{5}-\mathrm{P}[5]$ 1c: To a solution of $(\text { allyl })_{5}(\mathrm{Me})_{5}-\mathrm{P}[5] \mathbf{1 b}^{17 \mathrm{a}}$ ( $285 \mathrm{mg}, 0.323 \mathrm{mmol}, 1.0$ equiv) in EtOAc $(30 \mathrm{~mL})$ was added $\mathrm{Pd} / \mathrm{C}$ ( $10 \%$ wt, wetted with $55 \% \mathrm{H}_{2} \mathrm{O}, 285 \mathrm{mg}$ ). The resulting mixture was stirred under a $\mathrm{H}_{2}$ atmosphere at $25{ }^{\circ} \mathrm{C}$ for $24 \mathrm{~h}$, then filtered over a pad of celite, and concentrated to dryness. Column chromatography (EtOAc/ $n$-hexane, 5/95) afforded $1 \mathrm{c}$ as a white solid $(256 \mathrm{mg}, 0.287$ mmol, 89\%). ${ }^{1} \mathrm{H}$ NMR $\left(600 \mathrm{MHz}, \mathrm{CDCl}_{3}\right) \delta 6.80(\mathrm{~s}, 5 \mathrm{H}), 6.76(\mathrm{~s}$, $5 \mathrm{H}), 3.78(\mathrm{~s}, 10 \mathrm{H}), 3.77(\mathrm{t}, J=6.8 \mathrm{~Hz}, 10 \mathrm{H}), 3.67(\mathrm{~s}, 15 \mathrm{H}), 1.75-$ $1.69(\mathrm{~m}, 10 \mathrm{H}), 0.99(\mathrm{t}, J=7.4 \mathrm{~Hz}, 15 \mathrm{H}) .{ }^{13} \mathrm{C}\left\{{ }^{1} \mathrm{H}\right\} \operatorname{NMR}(151 \mathrm{MHz}$, $\left.\mathrm{CDCl}_{3}\right) \delta 149.6,149.1,127.3,127.2,114.0,113.1,68.9,54.8,28.6$, 22.0, 9.7. HRMS (ESI) $m / z\left[\mathrm{M}+\mathrm{NH}_{4}\right]^{+}$calcd for $\mathrm{C}_{55} \mathrm{H}_{74} \mathrm{NO}_{10}$ 908.5307, found 908.5278.

Variable-Temperature NMR Measurements. All ${ }^{1} \mathrm{H}$ NMR spectra were recorded using a Bruker Avance III $400 \mathrm{MHz}$ instrument with 32 scans. The $\Delta G^{\ddagger}$ values were calculated using the coalescence temperature $T_{\mathrm{c}}$ and the difference in chemical shifts $(\Delta v)$ measured at 203 and $273 \mathrm{~K}$, respectively. To determine $T_{\mathcal{c}}{ }^{1} \mathrm{H}$ NMR spectra were recorded at various temperatures from 203 to $343 \mathrm{~K}$ in toluene- $d_{8}$ or acetone- $d_{6}$. In a typical VT NMR experiment, a $1 \mathrm{mM}$ solution of $\mathrm{P}[5]$ was prepared by dissolving an appropriate amount in $500 \mu \mathrm{L}$ of toluene- $d_{8}$ and thorough mixing. To accurately determine $\Delta v$, the shimming was performed manually wherever poor shimming (i.e., poor resolution, broad or unsymmetrical peaks) was evidenced. To prevent artifacts like spinning sidebands, spinning was turned off wherever needed. The phasing of spectra and baseline were corrected automatically. The calculation of $\Delta G^{\ddagger}$ was performed using the following equation ${ }^{22}$

$$
\Delta G^{\ddagger}=8.314 T_{\mathrm{c}}\left[22.96+\log \left(\frac{T_{\mathrm{c}}}{\Delta \nu}\right)\right]
$$

X-ray Crystallography. Single crystals suitable for X-ray diffraction were grown by the vapor-vapor diffusion method, $\mathrm{EtOAc} / n$-hexane for $1 \mathrm{c}$ and $\mathrm{CHCl}_{3} / n$-hexane for 1d, then selected and mounted in inert oil under a cold gas stream, and their X-ray diffraction intensity data were collected on a Rigaku XtaLAB FRX diffractometer equipped with a Hypix6000HE detector, using $\mathrm{Cu} \mathrm{K} \alpha$ radiation $(\lambda=1.54184 \AA)$. By the use of Olex $2,{ }^{23}$ the structure was solved either (i) with the ShelXS structure solution program using Direct Methods or (ii) with the ShelXT structure solution program using direct methods or intrinsic phasing, ${ }^{24}$ refined with the ShelXL refinement package using least-squares minimization. ${ }^{25}$ The hydrogen atoms were set in calculated positions and refined as riding atoms with a common fixed isotropic thermal parameter. Selected details of the data collection and structural refinement of compounds $\mathbf{1 c}$ and $\mathbf{1 d}$ can be found in the Supporting Information, and full details are available in the corresponding CIF files (CCDC 1989352 and 1896020).

\section{ASSOCIATED CONTENT}

\section{Supporting Information}

The Supporting Information is available free of charge at https://pubs.acs.org/doi/10.1021/acs.joc.0c01464.

$\mathrm{X}$-ray data for compound $\mathbf{1 c}(\mathrm{CIF})$

$\mathrm{X}$-ray data for compound $\mathbf{1 d}$ (CIF)

${ }^{1} \mathrm{H},{ }^{13} \mathrm{C}$, and DNMR spectra, and X-ray data (PDF) 


\section{AUTHOR INFORMATION}

\section{Corresponding Authors}

Han Zuilhof - Institute for Molecular Design and Synthesis, School of Pharmaceutical Science \& Technology, Tianjin University, Tianjin 300072, P. R. China; Laboratory of Organic Chemistry, Wageningen University, 6703 WE Wageningen, The Netherlands; Department of Chemical and Materials Engineering, King Abdulaziz University, 21589 Jeddah, Saudi Arabia; 이이이.org/0000-0001-5773-8506; Email: Han.Zuilhof@wur.nl

Andrew C.-H. Sue - Institute for Molecular Design and Synthesis, School of Pharmaceutical Science \& Technology, Tianjin University, Tianjin 300072, P. R. China; (1) orcid.org/ 0000-0001-9557-2658; Email: andrew.sue@tju.edu.cn

\section{Authors}

Ke Du - Institute for Molecular Design and Synthesis, School of Pharmaceutical Science \& Technology, Tianjin University, Tianjin 300072, P. R. China; ○ orcid.org/0000-0002-17867327

Paul Demay-Drouhard - Institute for Molecular Design and Synthesis, School of Pharmaceutical Science \& Technology, Tianjin University, Tianjin 300072, P. R. China; Laboratory of Organic Chemistry, Wageningen University, 6703 WE Wageningen, The Netherlands; (1) orcid.org/0000-0003-22701177

Kushal Samanta - Institute for Molecular Design and Synthesis, School of Pharmaceutical Science \& Technology, Tianjin University, Tianjin 300072, P. R. China; Laboratory of Organic Chemistry, Wageningen University, 6703 WE Wageningen, The Netherlands; 1 orcid.org/0000-0002-74144475

Shunshun Li - Institute for Molecular Design and Synthesis, School of Pharmaceutical Science \& Technology, Tianjin University, Tianjin 300072, P. R. China

Tushar Ulhas Thikekar - Institute for Molecular Design and Synthesis, School of Pharmaceutical Science \& Technology, Tianjin University, Tianjin 300072, P. R. China

Haiying Wang - Institute for Molecular Design and Synthesis, School of Pharmaceutical Science \& Technology, Tianjin University, Tianjin 300072, P. R. China

Minjie Guo - Institute for Molecular Design and Synthesis, School of Pharmaceutical Science \& Technology, Tianjin University, Tianjin 300072, P. R. China

Barend van Lagen - Laboratory of Organic Chemistry, Wageningen University, 6703 WE Wageningen, The Netherlands

Complete contact information is available at:

https://pubs.acs.org/10.1021/acs.joc.0c01464

\section{Author Contributions}

"K.D. and P.D.-D. contributed equally. The manuscript was written through contributions of all authors. All authors have given approval to the final version of the manuscript.

\section{Notes}

The authors declare no competing financial interest.

\section{ACKNOWLEDGMENTS}

The authors are grateful for the highly useful suggestions obtained from reviewers of a previous version of this manuscript. This research was supported by National Science Foundation of China (no. 21871208; H.Z.), the Tianjin City
Thousand Talents Program (A.C.-H.S. and H.Z.), Wageningen University, and Tianjin University. The authors thank Prof. Xiangyang Zhang and all staff of Instrumental Analysis Center, School of Pharmaceutical Science and Technology, Tianjin University, for assistance in various characterizations.

\section{REFERENCES}

(1) (a) Ogoshi, T.; Kanai, S.; Fujinami, S.; Yamagishi, T.-a.; Nakamoto, Y. para-Bridged Symmetrical Pillar[5]arenes: Their Lewis Acid Catalyzed Synthesis and Host-Guest Property. J. Am. Chem. Soc. 2008, 130, 5022-5023. (b) Ogoshi, T.; Yamagishi, T.-a.; Nakamoto, Y. Pillar-Shaped Macrocyclic Hosts Pillar $[n]$ arenes: New Key Players for Supramolecular Chemistry. Chem. Rev. 2016, 116, 7937-8002. (c) Ogoshi, T. Pillararenes; Royal Society of Chemistry: Cambridge, 2016.

(2) Wolf, C. Dynamic Stereochemistry of Chiral Compounds; Royal Society of Chemistry: Cambridge, 2016.

(3) (a) Ogoshi, T.; Kitajima, K.; Fujinami, S.; Yamagishi, T.-a. Synthesis and X-ray Crystal Structure of a Difunctionalized Pillar[5]arene at A1/B2 Positions by in Situ cyclization and Deprotection. Chem. Commun. 2011, 47, 10106-10108. (b) Ogoshi, T.; Aoki, T.; Kitajima, K.; Fujinami, S.; Yamagishi, T.-a.; Nakamoto, Y. Facile, Rapid, and High-Yield Synthesis of Pillar[5]arene from Commercially Available Reagents and Its X-ray Crystal Structure. J. Org. Chem. 2011, 76, 328-331. (c) Strutt, N. L.; Fairen-Jimenez, D.; Iehl, J.; Lalonde, M. B.; Snurr, R. Q.; Farha, O. K.; Hupp, J. T.; Stoddart, J. F. Incorporation of an A1/A2-Difunctionalized Pillar[5]arene into a Metal-Organic Framework. J. Am. Chem. Soc. 2012, 134, 1743617439.

(4) Yang, W.; Samanta, K.; Wan, X.; Thikekar, T. U.; Chao, Y.; Li, S.; Du, K.; Xu, J.; Gao, Y.; Zuilhof, H.; Sue, A. C.-H. Tiara[5]arenes: Synthesis, Solid-State Conformational Studies, Host-Guest Properties, and Application as Nonporous Adaptive Crystals. Angew. Chem., Int. Ed. 2020, 59, 3994-3999.

(5) Ogoshi, T.; Kitajima, K.; Aoki, T.; Yamagishi, T.-a.; Nakamoto, Y. Effect of an Intramolecular Hydrogen Bond Belt and Complexation with the Guest on the Rotation Behavior of Phenolic Units in Pillar[5]arenes. J. Phys. Chem. Lett. 2010, 1, 817-821.

(6) (a) Böhmer, V.; Kraft, D.; Tabatabai, M. Inherently Chiral Calixarenes. J. Inclusion Phenom. Mol. Recognit. Chem. 1994, 19, 1739. (b) Zheng, Y.-S.; Luo, J. Inherently Chiral Calixarenes: A Decade's Review. J. Inclusion Phenom. Macrocyclic Chem. 2011, 71, 35-56. (c) Arnott, G. E. Inherently Chiral Calixarenes: Synthesis and Application. Chem. - Eur. J. 2018, 24, 1744-1754.

(7) (a) Szumna, A. Inherently Chiral Concave Molecules-from Synthesis to Applications. Chem. Soc. Rev. 2010, 39, 4274-4285. (b) Dalla Cort, A.; Mandolini, L.; Pasquini, C.; Schiaffino, L. "Inherent Chirality" and Curvature. New J. Chem. 2004, 28, 11981199. (c) Fa, S.; Kakuta, T.; Yamagishi, T.-a.; Ogoshi, T. Conformation and Planar Chirality of Pillar $[n]$ arenes. Chem. Lett. 2019, 48, 1278-1287.

(8) Wang, X.; Chen, R.; Sue, A. C.-H.; Zuilhof, H.; Aquino, A.; Lischka, H. Introduction of Polar or Nonpolar Groups at the Hydroquinone Units Can Lead to the Destruction of the Columnar Structure of Pillar[5] arenes. Comput. Theor. Chem. 2019, 1161, 1-9.

(9) Ogoshi, T.; Masaki, K.; Shiga, R.; Kitajima, K.; Yamagishi, T.-a. Planar-Chiral Macrocyclic Host Pillar[5]arene: No Rotation of Units and Isolation of Enantiomers by Introducing Bulky Substituents. Org. Lett. 2011, 13, 1264-1266.

(10) (a) Ogoshi, T.; Shiga, R.; Yamagishi, T.-a.; Nakamoto, Y. Planar-Chiral Pillar[5]arene: Chiral Switches Induced by Multiexternal Stimulus of Temperature, Solvents, and Addition of Achiral Guest Molecules. J. Org. Chem. 2011, 76, 618-622. (b) Park, J.; Choi, Y.; Lee, S. S.; Jung, J. H. Critical Role of Achiral Guest Molecules in Planar Chirality Inversion of Alanine-Appended Pillar[5]arenes. Org. Lett. 2019, 21, 1232-1236. 
(11) Ogoshi, T.; Kitajima, K.; Aoki, T.; Fujinami, S.; Yamagishi, T.a.; Nakamoto, Y. Synthesis and Conformational Characteristics of Alkyl-Substituted Pillar[5]arenes. J. Org. Chem. 2010, 75, 3268-3273.

(12) (a) Zhang, Z.; Xia, B.; Han, C.; Yu, Y.; Huang, F. Synthesis of Copillar[5] arenes by Co-oligomerization of Different Monomers. Org. Lett. 2010, 12, 3285-3287. (b) Han, C.; Zhang, Z.; Yu, G.; Huang, F. Syntheses of a Pillar[4]arene[1]quinone and a Difunctionalized Pillar[5] arene by Partial Oxidation. Chem. Commun. 2012, 48, 98769878. (c) Strutt, N. L.; Zhang, H.; Stoddart, J. F. Enantiopure Pillar[5] arene Active Domains within a Homochiral Metal-Organic Framework. Chem. Commun. 2014, 50, 7455-7458. (d) Chen, J.-F.; Yin, X.; Wang, B.; Zhang, K.; Meng, G.; Zhang, S.; Shi, Y.; Wang, N.; Wang, S.; Chen, P. Planar Chiral Organoboranes with Thermoresponsive Emission and Circularly Polarized Luminescence: Integration of Pillar[5]arenes with Boron Chemistry. Angew. Chem., Int. Ed. 2020, 59, 11267-11271.

(13) Strutt, N. L.; Schneebeli, S. T.; Stoddart, J. F. Stereochemical Inversion in Difunctionalised Pillar[5]arenes. Supramol. Chem. 2013, $25,596-608$

(14) (a) Ogoshi, T.; Furuta, T.; Yamagishi, T.-a. Chiral Supramolecular Polymers Consisting of Planar-Chiral Pillar[5]arene Enantiomers. Chem. Commun. 2016, 52, 10775-10778. (b) AlAzemi, T. F.; Vinodh, M.; Alipour, F. H.; Mohamod, A. A. Chiral Discrimination of 2-Heptlyaminium Salt by Planar-Chiral Monohydroxy-Functionalized Pillar[5]arenes. Org. Chem. Front. 2019, 6, 603-610. (c) Xiao, C.; Liang, W.; Wu, W.; Kanagaraj, K.; Yang, Y.; Wen, K.; Yang, C. Resolution and Racemization of a Planar-Chiral A1/A2-Disubstituted Pillar[5] arene. Symmetry 2019, 11, 773.

(15) Strutt, N. L.; Zhang, H.; Schneebeli, S. T.; Stoddart, J. F. Functionalizing Pillar $[n]$ arenes. Acc. Chem. Res. 2014, 47, 2631-2642.

(16) (a) Kou, Y.; Tao, H.; Cao, D.; Fu, Z.; Schollmeyer, D.; Meier, H. Synthesis and Conformational Properties of Nonsymmetric Pillar[5] arenes and Their Acetonitrile Inclusion Compounds. Eur. J. Org. Chem. 2010, 2010, 6464-6470. (b) Zhang, Z.; Luo, Y.; Xia, B.; Han, C.; Yu, Y.; Chen, X.; Huang, F. Four Constitutional Isomers of BMpillar[5]arene: Synthesis, Crystal Structures and Compexation with $n$-Octyltrimethyl Ammonium Hexafluorophosphate. Chem. Commun. 2011, 47, 2417-2419. (c) Al-Azemi, T. F.; Vinodh, M.; Alipour, F. H.; Mohamod, A. A. Constitutional Isomers of Pentahydroxyl-Functionalized Pillar[5]arenes: Synthesis, Characterization, and Crystal Structures. J. Org. Chem. 2017, 82, 10945-10952. (d) Ding, J.; Chen, J.; Mao, W.; Huang, J.; Ma, D. A New Synthetic Method for Nonsymmetric Pillar[5] arenes with Simple Isolation and Improved Yield. Org. Biomol. Chem. 2017, 15, 7894-7897. (e) Peng, C.; Liang, W.; Jia, J.; Fan, C.; Kanagaraj, K.; Wu, W.; Cheng, G.; Su, D.; Zhong, Z.; Yang, C. Pyrene-tiaraed Pillar[5]arene: Strong Intramolecular Excimer Emission Applicable for Photo-Writing. Chin. Chem. Lett. 2020, DOI: 10.1016/j.cclet.2020.03.079. (f) Fa, S.; Sakata, Y.; Akine, S.; Ogoshi, T. Non-Covalent Interactions Enable the Length-Controlled Generation of Discrete Tubes Capable of Guest Exchange. Angew. Chem., Int. Ed. 2020, 59, 9309-9313.

(17) (a) Guo, M.; Wang, X.; Zhan, C.; Demay-Drouhard, P.; Li, W.; Du, K.; Olson, M. A.; Zuilhof, H.; Sue, A. C.-H. Rim-Differentiated $C_{5}$-Symmetric Tiara-Pillar[5]arenes. J. Am. Chem. Soc. 2018, 140, 7477. (b) Demay-Drouhard, P.; Du, K.; Samanta, K.; Wan, X.; Yang, W.; Srinivasan, R.; Sue, A. C.-H.; Zuilhof, H. Functionalization at Will of Rim-Differentiated Pillar[5]arenes. Org. Lett. 2019, 21, 3976-3980. (c) Du, K.; Sue, A. C.-H. The Trouble with Five: New Synthetic Strategies toward $C_{5}$-Symmetric Pillar[5]arenes and Beyond. Synlett 2019, 30, 2209-2215.

(18) (a) Ogoshi, T.; Shiga, R.; Hashizume, M.; Yamagishi, T.-a. "Clickable" Pillar[5]arenes. Chem. Commun. 2011, 47, 6927-6929. (b) Zhang, F.; Ma, J.; Sun, Y.; Boussoura, I.; Tian, D.; Li, H.; Jiang, L. Fabrication of a Mercaptoacetic Acid Pillar[5]arene assembled nanochannel: a Biomimetic Gate for Mercury Poisoning. Chem. Sci. 2016, 7, 3227-3233.

(19) Al-Azemi, T. F.; Vinodh, M.; Alipoura, F. H.; Mohamoda, A. A. An Alternative Route for the Synthesis of Hydroxylated Pillar[5]arene-Based Amphiphiles. Org. Biomol. Chem. 2018, 16, 7513-7517.
(20) (a) Ji, J.; Li, Y.; Xiao, C.; Cheng, G.; Luo, K.; Gong, Q.; Zhou, D.; Chruma, J. J.; Wu, W.; Yang, C. Supramolecular Enantiomeric and Structural Differentiation of Amino Acid Derivatives with Achiral Pillar[5] arene Homologs. Chem. Commun. 2020, 56, 161-164. (b) Chen, Y.; Fu, L.; Sun, B.; Qian, C.; Wang, R.; Jiang, J.; Lin, C.; Ma, J.; Wang, L. Competitive Selection of Conformation Chirality of Water-Soluble Pillar[5]arene Induced by Amino Acid Derivatives. Org. Lett. 2020, 22, 2266-2270.

(21) (a) Ogoshi, T.; Akutsu, T.; Yamafuji, D.; Aoki, T.; Yamagishi, T.-a. Solvent- and Achiral-Guest-Triggered Chiral Inversion in a Planar Chiral pseudo [1]Catenane. Angew. Chem., Int. Ed. 2013, 52, 8111-8115. (b) Yao, J.; Wu, W.; Liang, W.; Feng, Y.; Zhou, D.; Chruma, J. J.; Fukuhara, G.; Mori, T.; Inoue, Y.; Yang, C. Temperature-Driven Planar Chirality Switching of a Pillar[5]areneBased Molecular Universal Joint. Angew. Chem., Int. Ed. 2017, 56, 6869-6873. (c) Lee, E.; Ju, H.; Park, I.-H.; Jung, J. H.; Ikeda, M.; Kuwahara, S.; Habata, Y.; Lee, S. S. pseudo[1]Catenane-Type Pillar[5]thiacrown Whose Planar Chiral Inversion is Triggered by Metal Cation and Controlled by Anion. J. Am. Chem. Soc. 2018, 140, 9669-9677. (d) Yang, Y.-F.; Hu, W.-B.; Shi, L.; Li, S.-G.; Zhao, X.-L.; Liu, Y. A.; Li, J.-S.; Jiang, B.; Ke, W. Guest-Regulated Chirality Switching of Planar Chiral pseudo[1]Catenanes. Org. Biomol. Chem. 2018, 16, 2028-2032. (e) Xiao, C.; Wu, W.; Liang, W.; Zhou, D.; Kanagaraj, K.; Cheng, G.; Su, D.; Zhong, Z.; Chruma, J. J.; Yang, C. Redox-Triggered Chirality Switching and Guest-Capture/Release with a Pillar[6]arene-Based Molecular Universal Joint. Angew. Chem., Int. Ed. 2020, 59, 8094-8098.

(22) Sandström, V. J. Dynamic NMR Spectroscopy; Academic Press: London, 1982.

(23) Dolomanov, O. V.; Bourhis, L. J.; Gildea, R. J.; Howard, J. A. K.; Puschman, H. OLEX2: A Completes Structure Solution, Refinement and Analysis Program. J. Appl. Crystallogr. 2009, 42, $339-341$.

(24) Sheldrick, G. M. A Short History of SHELX. Acta Crystallogr., Sect. A: Found. Crystallogr. 2008, 64, 112-122.

(25) Sheldrick, G. M. Crystal Structure Refinement with SHELXL. Acta Crystallogr., Sect. C: Struct. Chem. 2015, 71, 3-8. 